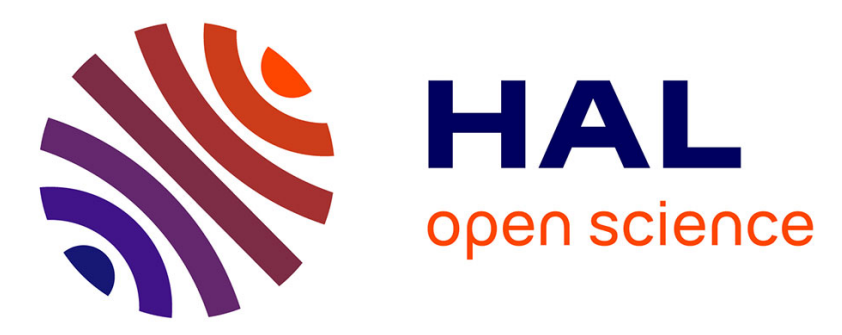

\title{
A probabilistic approach to predict the very high-cycle fatigue behaviour of spheroidal graphite cast iron structures
}

Isabelle Chantier, Véronique Bobet, René Billardon, François Hild

\section{- To cite this version:}

Isabelle Chantier, Véronique Bobet, René Billardon, François Hild. A probabilistic approach to predict the very high-cycle fatigue behaviour of spheroidal graphite cast iron structures. Fatigue and Fracture of Engineering Materials and Structures, 2000, 23 (2), pp.173-180. 10.1046/j.1460-2695.2000.00228.x . hal-02342795

\section{HAL Id: hal-02342795 \\ https://hal.science/hal-02342795}

Submitted on 4 Nov 2019

HAL is a multi-disciplinary open access archive for the deposit and dissemination of scientific research documents, whether they are published or not. The documents may come from teaching and research institutions in France or abroad, or from public or private research centers.
L'archive ouverte pluridisciplinaire HAL, est destinée au dépôt et à la diffusion de documents scientifiques de niveau recherche, publiés ou non, émanant des établissements d'enseignement et de recherche français ou étrangers, des laboratoires publics ou privés. 


\title{
A probabilistic approach to predict the very high-cycle fatigue behaviour of spheroidal graphite cast iron structures
}

\author{
I. CHANTIER, V. BOBET, ' R. BILLARDON and F. HILD*
}

LMT-Cacban, ENS de Cacban, CNRS, Université Paris 6, 61 avenue du Président Wilson, F-94235 Cacban Cedex, France, ${ }^{1}$ Renault Tecbnocentre, Direction de la Rechercbe, Service 64230, 1 avenue du Golf, F-78288 Guyancourt, Cedex, France

ABSTRACT A new probabilistic approach is developed to study structures made of spheroidal graphite cast iron and subjected to very high-cycle fatigue. Until now, the probabilistic approach was based on $S-N$ curves obtained from experiments carried out only until $10^{7}$ cycles. To validate this approach, failure predictions relating to the safety of components are computed and compared to experimental results. In addition to this development, an extension is proposed in order to improve the very long life assessment of complex structures. An extrapolation of the previous fatigue results to $10^{9}-10^{11}$ cycles illustrates the error made on cumulative failure probabilities. Finally, the respective influence of the casting flaw distribution, volume and stress field heterogeneity within specimens and industrial components is studied.

Keywords very high-cycle fatigue, probabilistic approach, casting flaw distribution, volume effect, stress heterogeneity effect, surface effect.

NOMENCLATURE

$a, a_{M}=$ current and maximum flaw size

$a_{\mathrm{c}}, a_{\mathrm{c} 0}, a_{\mathrm{th}}=$ critical, initial critical or threshold flaw size

$a_{0}, a_{\mathrm{N}}=$ flaw size after 0 or $N$ cycles

$B_{\alpha \beta}=$ Euler function of the first kind

$C, n, m=$ parameters of the crack propagation law

$f_{0}, f_{\mathrm{N}}=$ initial and current flaw size distributions

$g=$ function modelling the effect of the load ratio

$H_{\beta+1}^{\star}, H_{\beta+1}=$ stress heterogeneity factors

$K_{\mathrm{c}}, K_{\mathrm{th}}=$ critical and threshold stress intensity factors

$K_{\min }, K_{\max }=$ minimum and maximum stress intensity factors

$N, N_{\mathrm{F}}=$ number of cycles and cycles to failure, respectively

$P_{\mathrm{F} 0}, P_{\mathrm{F}}=$ cumulative failure probability of an element and a structure

$R=$ load ratio

$S_{\text {th }}=$ threshold stress

$V_{0}, V=$ volume of an element and a structure

$V_{\mathrm{eff}}^{\star}=$ effective volume

$W=$ positive dimensionless parameter

$x_{\mathrm{th}}=$ dimensionless stress

$Y=$ geometric dimensionless parameter

$\alpha, \beta=$ parameters of a beta function

$\Delta K_{\mathrm{eff}}=$ effective stress intensity range

$\sigma=$ equivalent stress (e.g. maximum principal stress)

$\sigma_{0}=$ scale parameter

$\sigma_{\text {max }}, \sigma_{\mathrm{F}}=$ maximum and failure stresses

$\varphi=$ function

$\Phi=$ diameter

$\Omega_{0}, \Omega=$ volume element, structure

$\langle\cdot\rangle=$ positive part of 


\section{INTRODUCTION}

This study is directly related to the efforts made by car manufacturers to improve the life assessment for safe components, e.g. suspension arms, which are made of spheroidal graphite (SG) cast iron and subjected to very high-cycle fatigue (VHCF) loadings. The industrial challenge consists of designing better components that are also cheaper and manufactured faster. To reach this goal in the case of safe cast safety components, the lifing procedures must integrate a fatigue analysis that is reliable enough to avoid tests and the rejection of components, i.e. to reduce the time for design, development and non-destructive testing after the manufacturing process. Structural reliability analyse ${ }^{1}$ could be used to evaluate the fatigue life of cast components. However, most of the analyses do not account for the actual cause of failure. In this paper, it is proposed to introduce a mechanism-based probabilistic model.

This study is a first attempt to justify the use of a probabilistic approach for the design of such components up to the gigacycle regime. The fatigue strength of cast parts is generally reduced by the presence of initial casting flaws that are more or less randomly distributed within the material. Under cyclic loading conditions, microcracks propagate from these initial flaws. Finally, macrocrack propagation usually takes place first in a stable and then in an unstable way. However, macrocrack propagation represents only a negligible fraction of the life of components subjected to high- or very high-cycle fatigue loadings. It follows therefore that any approach used to predict very high-cycle fatigue failure should be supported by the weakest link theory. ${ }^{2}$ Hence, it is assumed that the components remain macroscopically elastic, and that the microscopic evolution of the initial flaws can be described up to failure by a modified Paris' law. The observation of scattered results on Wöhler diagrams of SG cast iron confirms the need for a probabilistic approach.

In this paper, the material properties are first listed and the framework of the probabilistic approach is then recalled. Secondly, the failure probabilities depending upon stress level and initial flaw size distributions within the components are defined. Thirdly, predictions based on this probabilistic model are analysed and an extrapolation of this approach to the gigacycle regime is proposed. Finally, so-called DVH effects (where D stands for flaw size distribution, $\mathrm{V}$ for volume and $\mathrm{H}$ for stress heterogeneity) ${ }^{3}$ are shown.

\section{THE STUDIED MATERIAL}

The \% wt composition of the ferritic SG cast iron studied here was: $3.8 \mathrm{C}, 3.21 \mathrm{Si}, 0.01 \mathrm{Mg}, 0.04 \mathrm{~S}$ and $0.007 \mathrm{P}$ with the remainder ferrite. This material contains less than $5 \%$ of pearlite. The main microstructural characteristics are: mean graphite nodule diameter $=17 \mu \mathrm{m}$, ferritic grain size $=15-22 \mu \mathrm{m}$, mean distance between nodules $=80 \mu \mathrm{m}$ [Fig. 1(a)]. For as-cast components, the tensile properties are: yield stress $=360 \mathrm{MPa}$, ultimate strength $=490 \mathrm{MPa}$, elongation $=4 \%$, Young's modulus $=150 \mathrm{GPa}$. Figure $1(\mathrm{~b})$ shows typical casting flaws leading to failure. If these flaws are modelled by cracks that experience stable propagation, the corresponding stress intensity factor can be defined by $K=Y \sigma \sqrt{a}$ and the propagation law by a modified Paris' law ${ }^{5,6}$

$$
\frac{\mathrm{d} a}{\mathrm{~d} N}=C \Delta K_{\mathrm{cff}}^{n} \quad \text { with } \quad \Delta K_{\mathrm{eff}}=\frac{K_{\mathrm{max}} g(R)-K_{\mathrm{rh}}}{K_{\mathrm{c}}-\frac{K_{\mathrm{th}}}{g(R)}}
$$
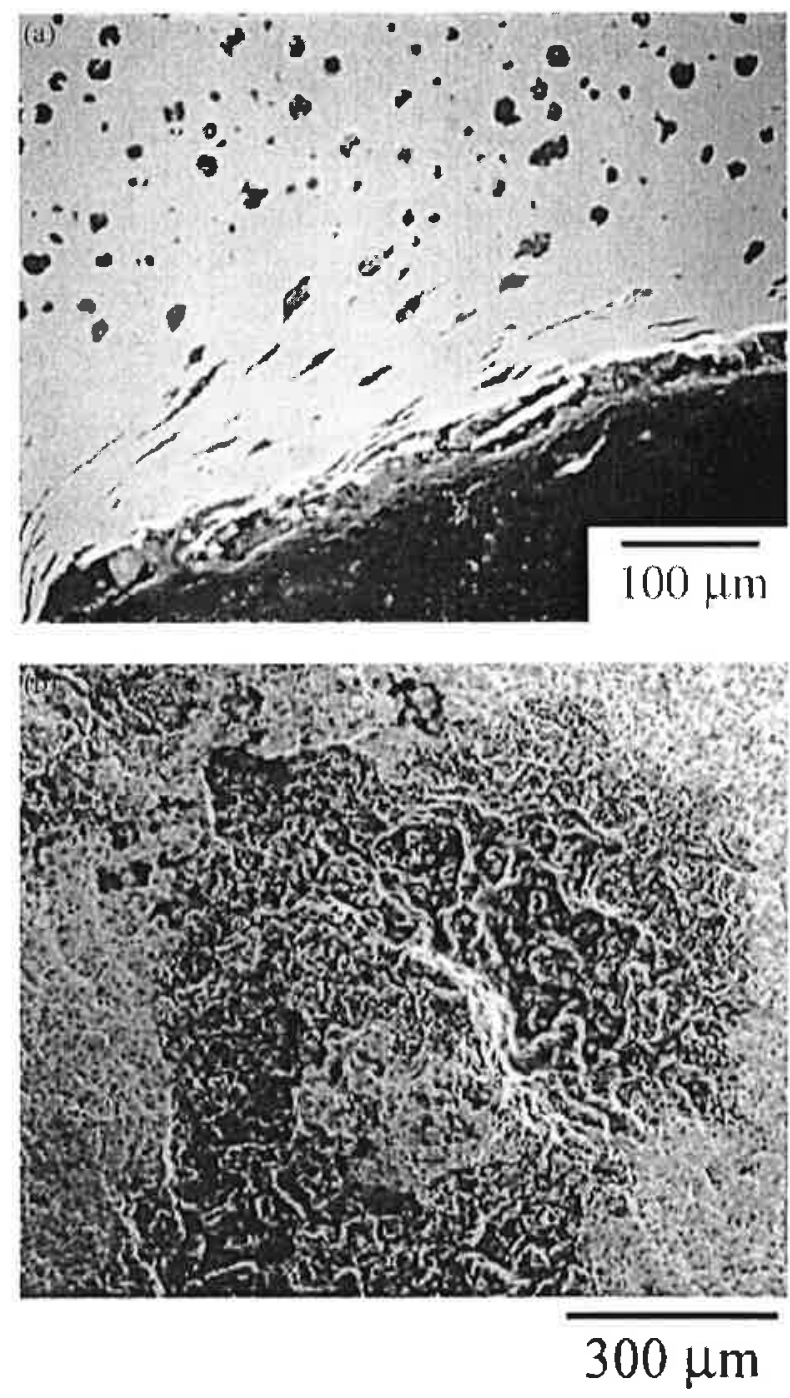

Fig. 1 Typical microstructures of SG cast iron. (a) Graphite nodules in the vicinity of an as-cast surface. (b) A microshrinkage cavity observed on the fatigue fracture surface of a suspension arm. 
and

$g(R)=\frac{1-R}{1-m R}$ with $R=\frac{K_{\min }}{K_{\max }}$

In the case of VHCF, $K_{\max } g(R)$ is close to the threshold stress intensity factor $K_{\mathrm{rl}}$, for which the non-propagation condition is given by $K_{\operatorname{mix}} g(R)<K_{\mathrm{th}}$. 'I'he criterion for local failure considers that $K_{\operatorname{lnax}} \geqslant K_{\mathrm{c}}$, and the effective stress intensity range $\Delta K_{\text {eff }}$ is positive. By using this criterion, one can determine a critical Haw size $a_{c}$ associated to a stress level $\sigma_{\text {max }}$. By integrating Eq. (1), the number of cycles to fathere $N_{\mathrm{F}}$ is found to be a function of the initial flaw size $n_{\mathrm{c}(1)}$, the maximum flaw size $a_{\mathrm{M}}$, the load ratio $R$, the latigue limit for a volume clement with the largest Haw size $S_{\text {In }}$ and a lunction $\varphi^{\prime}$

$\varphi\left(\sqrt{\frac{a_{\mathrm{c}}}{a_{\mathrm{M}}}}\right)-\varphi\left(\sqrt{\frac{a_{\mathrm{c} 0}}{a_{\mathrm{M}}}}\right)=\frac{C}{a_{\mathrm{M} 1}}\left(\frac{g(R) K_{\mathrm{th}}}{K_{\mathrm{c}}-\frac{K_{\mathrm{th}}}{g(R)}}\right)^{\prime \prime}\left(\frac{\sigma_{\max }}{S_{\mathrm{th}}}\right)^{n} N_{\mathrm{F}}$

with $\quad S_{1 \mathrm{~h}}=\frac{K_{1 \mathrm{~h}}}{Y_{g}(R) \sqrt{\pi_{M}}}$

When $n=2$, the function $\phi$ is expressed as"

$\varphi(x)=2 \ln \left(x-x_{1 h}\right)-\frac{2 x}{\left(x-x_{\mathrm{th}}\right)}$ with $x_{\mathrm{ih}}=\frac{S_{\mathrm{th}}}{\sigma_{\max }}$

The fatigue behaviour of this material shows scattered results on Wöhler $S-N$ diagrams. For a given load ratio $(R=0.1)$ and a similar number of cycles to failure, the failure stress level may vary by a factor of 1.6 for different specimens subjected to tension (Fig. 2). 'Iwo kinds of flaws can be distinguished by SEM analysis, viz. degenerated graphite nodules that

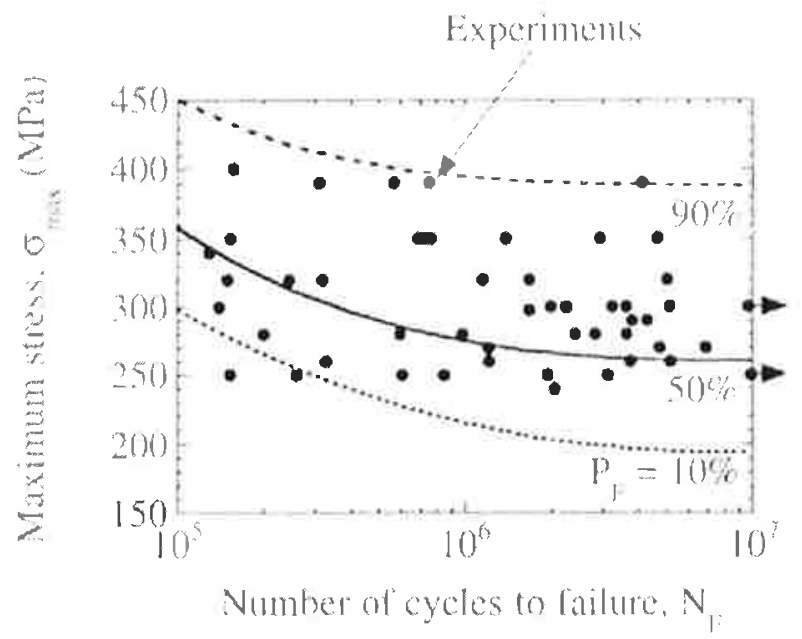

Fig. 2 Fatigue experiments and predicted cumulative failure probalbilities in cyclic tension $(R=0.1)$. are present at the as-cast fiee surfiace [Fig. 1(a)], and microshrinkage cavities that exist within the bulk material as well as close to the as-cast free surface [Fig. 1(b)]. These observations justify the use of a probability density function $f_{0}$ to describe the flaw size distribution modelled by a beta density"

$f_{0}(a)=\frac{a^{x}\left(a_{M}-a\right)^{\beta}}{B_{x \beta} a_{M 1}^{x+\beta+1}}$ with $B_{x \beta}=\int_{0}^{1} t^{x}(t-1)^{\beta} \mathrm{d} t$

where $\alpha$ and $\beta$ are adjustable parameters, and $a_{M}$ is the maximum flaw size $\left(0 \leqslant n \leqslant u_{M}\right)$.

By performing systematic SFM observations of 50 fractured surfaces, the parameters of the flaw size clistribution are identified as: $\alpha=2.3, \beta=18$ and $a_{\mathrm{M}}=400 \mu \mathrm{m}$, with $V_{0}=340 \mathrm{~mm}^{3}$. Consequently, the microshrinkage cavities can be associated with physically short cracks.? Secondly, the material parameters of the propayation lnw can be identified: $C / n_{M}=5.9 \times 10^{-5}, K_{1 h} / K_{c}=0.33$, $n t=0.59, n=2, S_{1 \mathrm{~h}}=105 \mathrm{MPa}, Y=2$." The previous material parameters were used to evaluate the tensioncompression data obtained on SG cast iron up to $10^{7}$ cycles to failure. $\Lambda$ good agrecment was found for test results with $R=0.1$ (see Fig. 2) and $R=-1$." These paraneters will be used throughout the present paper, although it is worth noting that corrosive environments could lead to other crack propagation parameters in the vicinity of a free surface ${ }^{8}$ and under complex nultiaxial stress states." In particular, it is well known that a saltwater environment that cxists in off-shore and ncarshore structures can seriously aflect the fatigue resistance of materials, components and structures. However, this aspect of our work will involve a further study that takes account of the complex loading pattern to which suspension arms arc subjected.

'llac next section is devoted to the definition of the cumulative failure probability associated with the stable propagation of initial cracks under cyclic loading conditions. The initial haws are modelled as penny-shaped cracks, whose normal is perpendicular to the direction of the local maximum principal stress.

\section{A PROBABILISTIC TREATMENT OF FATIGUE FAILURE}

For the sake of simplicity, only the case of constant load levels is cliscussed. The stress $\sigma_{\max }$ represents the maximum of an equivalent stress (c.g. maximum principal stress) over one loading cycle. We consicler an element $\Omega_{0}$ of volume $V_{0}$. It contains initial flaws modelled by penny-shaped cracks of size $2 a_{0}$ and randomly distributed (the initial flaw size distribution is $f_{0}$ ). Under cyclic luading, the initial density $f_{0}$ evolves with the number of cycles $N$ to become equal to $f_{N}$. The cumulative failure probability $P_{\mathrm{ro}}$ depends upon $f_{N}$, and is the 
probability of finding flaws greater than $a_{c}$ after $N$ cycles

$P_{100}=\int_{w_{c}}^{+\infty} f_{N}(a) \mathrm{d} a$ with $a_{\mathrm{c}}=\left(\frac{K_{\mathrm{c}}}{Y \sigma_{\max }}\right)^{2}$

It is assumed that there is no nucleation of thaws during the whole load history: the probability of finding a flaw: size equal to $a_{N}$ after $N$ cycles is the same as the probability of finding an initial flaw $a_{0}$. I3y introducing the initial crack size $a_{\mathrm{e}^{0}}$ that becomes critical after $N$ cycles $\left[\sec \mathrm{L}\right.$ q. (3)], $P_{\text {fon }}$ can be rewritten as ${ }^{6}$

$P_{100}=\int_{\left({ }^{\mathrm{c}} \mathrm{l}\right)}^{+\infty} f_{0}(a) \mathrm{d} x$

Stating that $N_{\mathrm{I}}$ incroases is equivalent to saying that the critical flaw size a decteases: more and more critical flaws appear when $N_{\mathrm{F}}$ increases. By noting that crack propagation only occurs when $K_{\text {max }} g(R)>K_{1 h}$, a lower bound to the cumulative failure probability is given by

$P_{\Gamma n t}=\int_{\pi, \mathrm{h}}^{+\infty} f_{n}(n) \mathrm{d} a$ with $\pi_{1 \mathrm{~h}}=\left[\frac{K_{\mathrm{th}}}{Y_{g}(R) \sigma_{\max }}\right]^{2}$

This case cortesponds to the limiting condition $N_{1} \rightarrow+\infty$. lior a given suess level $\sigma_{1 \text { mix }}$, the value of $a_{1 \mathrm{l}}$ denotes the smallest flaw sim that is able to propagate. 'I This allows one to compute the fatigue limits associated with the crack propagation law given in the previous section. Ficpuations (7) and (8) show that the most important aspect related to failure is the dimension of the righthand side tail of the flaw size distribution.

The generalization of the reliability analysis of the volume clement $\Omega_{0}$ to a complex structure $\Omega$ of volume $V$ can be obtained by assuming that only flaws initially present within the material cause the failore of the structure. In addition, the interactions between flaws are neglected. In the framework of the weakest link theory, the cumulative failure probability $P_{F}$ of a structure $\Omega$, for any loading conditions, is related to $P_{F(1)}$ by

$P_{\mathrm{T}^{i}}=1-\exp \left[\frac{1}{V_{0}^{\prime}} \iiint_{\Omega} \ln \left(1-P_{\mathrm{T} 0}\right) \mathrm{d} V\right]$

To be critical, a defect needs to be in the proplagation regime (i.e. $K_{111: 1 x}>K_{1 / 1}$ ) and so the weakest link is not necessarily the largest defect in the structure. Therefore, the knowledge of the whole distribution is important, especially its right-hand sicle tail. In tensioncompression, li,g. (9) becomes

$P_{\mathrm{F}}=1-\left(1-P_{\mathrm{F} 0}\right)^{P^{\prime} P_{13}}$

Thus, according to ligs (7) and (10), a constant cumulative failure probability $P_{\mathrm{T}}$ is equivalent to considering a constant value $a_{\mathrm{c}: 1}$, for a given flaw size distribution $f_{0}$. 'This result shows that the crack propagation parameters can be identified from the study of one constant cumblative failure probability (e.g. $50 \%$ ) in tensioncompression,"

\section{PREDICTIONS ON SUSPENSION ARMS}

Fatigue tests were carried out on suspension arms with a mechanical system which allows one to prescribe biaxial in-plane loading, along two axes $X$ and $Y$ at point $C$ (Fig. 3). These tests were performed for Renault by CEIIM. The analysis of the fatigue results again shows important scatter on the $F-N$ diagram (Fig. 4). According to the obscrvations of failure locations, the initiation sites are mainly located in the region indicated in Fig. 3, that is close to the knee joint. By SIEM analysis, the same classes of flaws were observed as those in as-cast samples.' As a first approximation, we consider that the

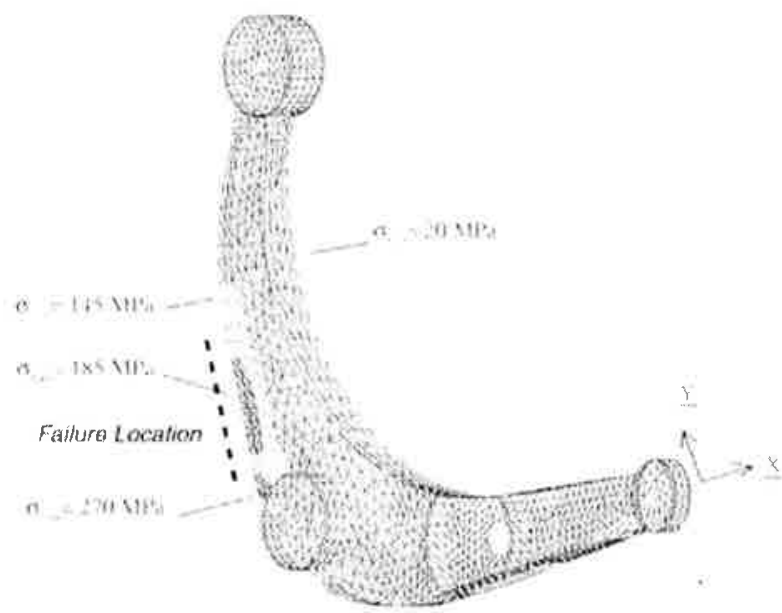

Fig. 3 Contouts of maximum principal stress and failure locarion on suspension anms observed in tests and computations.

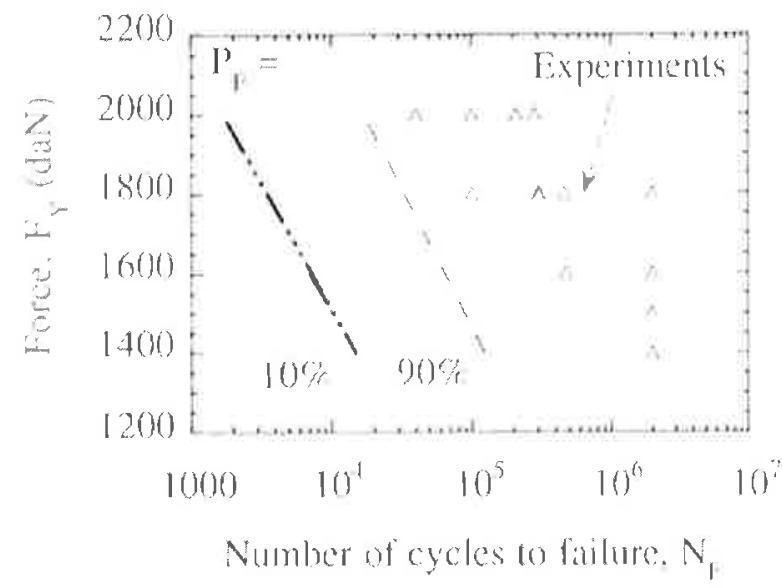

Fig. 4 Predicted comstant cumblacive failure prohabilities compared to experiments carried out on a suspension arm with $R=0.1^{5}$ 
relevant flaw size distribution is identical in both cases Noting thit as-cast and clouble shot-peened suspension arms can be mounted on cirs, a physical layer at the free surface is induced by shot-peening. During this process, the degencrated nodules are crushed [Fig. 1(a)] so thit the original notch effect they induce disappears.

'To assess the predictive capacity of the probabilistic approach, a comparison between fatigue tests carried out on double shot-pecned suspension arms and results predicted by the model are now performed. A programme, ASTAR, was developed to evaluate the reliability of components subjected to cyclic loading. "This programme allows one to predict the local failure probabilities and the global failure probability of a structure, and integrates the clfects of component volume, stress ficld heterogeneity and flaw size distribution which will be discusscel later:

'T he progranme ASTAR is used as a postprocessor of an elastic FE analysis to determine the stress field in structures: at each integration point, the equivalent stress is computed (c.g. maximum principal stress). To this cquivalent stress corresponds an initial flaw size $a_{\mathrm{c} n}$ for a given number of cycles to failure $N_{\mathrm{l}}$. This flaw size is computed by integration of F.q. (1) through a Newton method. "1 'The failure probability $P_{\mathrm{re}}^{\prime}$ of a finite element $j$ can be calculated by using a Gauss integration of local failure probabilities $P_{\text {Fin }}^{i}$ so that $P_{\text {re: }}^{j}$ depends on the element volume $V_{c}^{j}$, the number $n_{p}$ ol integration points for this element and the weight $w_{\text {; }}$ associated to each integration point

$\left.\ln \left(1-P_{\text {lee }}^{j}\right)=\frac{V_{e}^{j}}{V_{0}} \sum_{i=1}^{n} \ln \left(1-P_{l i 1}^{i}\right) * w_{i}\right]$

where $P$ ilo flenotes the eumulative failure probability at point $i$, computed by using Eq. (7). The failure probability of the whole structure $P_{\mathrm{F}^{\text {r }}}$ is then computed as

$\left.P_{1:}=1-\exp \right)\left[\sum_{j=1}^{n_{\mathrm{L}}} \ln \left(1-p_{r_{i s}}^{j}\right)\right]$

where $n_{e}$ is the number of elements of the structure.

The parameters iclentified for the flaw distribution and the propagation law constitute the only information needed to run $\Lambda S^{\prime} T \Lambda R$. For a given Haw size distribution, the constant curnulative failure probabilities of 10 and $90 \%$ are drawn on an $F_{\mathrm{Y}}-N_{\mathrm{Ii}}$ plot with $R=0.1$ (Fig. 4). The experimental fatigue data are reasonably close to the predicted failure probabilities. By inspection of the contours of locial cumulative failure probabilities, the most likely sites of failure correspond to those observed experimentally (see Irig. 3). These results confirm that the flaw location with respect to the stress field is of utmost importance. 'Ihis means that to be critical a defect needs to be subjected to a mitnimum stress level (such that $\Delta K_{\text {eff }} \geqslant 0$ ). Moreover, this cilculation represents a first pessinistic but reasonable approach for two main reasons: the residual compressive stresses clue to the double shot-peening are not taken into account and a single flaw size distribution in the suspension arm (identical to that observed on samples) is considered. In the next section, an cndurance limit is defined thanks to an extrapolation to the gigacycle regime by analysing the evolutions of cumulative failure probabilities.

\section{EXTRAPOLATION TO THE GIGACYCLEREGIME}

Most fatigue tests performed on specimens to identify Wöhler diagrams ate designed to reach failure at a number of cycles close to a maximum of 10 or 20 million. For components, e.g. suspension alms, experiments are often stopped after two million cycles. Hence, the entire endurance limit range is not really well defined.

Extrapolation to $10^{4}-10^{11}$ cycles of the results obtained up to $10^{7}$ eycles allows one to detcrmine the crror made on the fatigue life in the case of $S G$ cast iron components. The $S-N$ curves that are plotted correspond to different small values of cumulative failure probabilities and are cxtrapolated from the results given in Ref. [6] and briefly recalled in the previous sections. For a given applied stress $\sigma_{\max }$, the larger $P_{\text {ron }}$, the larger the number of cycles to failure. 'To quantify the error' for each given $P_{100}(0,0.01,0.1,1$ and $10 \%)$, the conventional fatigue limit (defined at $10^{7} \mathrm{cycles}$ ) normalised by the applied stress is plotted versus the number of cycles to failure nomalised by $10^{7}$ cycles (Fig. 5). Considering that for the smallest $P_{1 * 0}(0 \%)$ the error is as small as $3 \%$, it could be rapidly concluded that in the case of the SCr cast iron components, performing expensive tests up to $10^{9}-10^{11}$ cyeles is not necessary. However, it is worth noticing that crack propagation in the

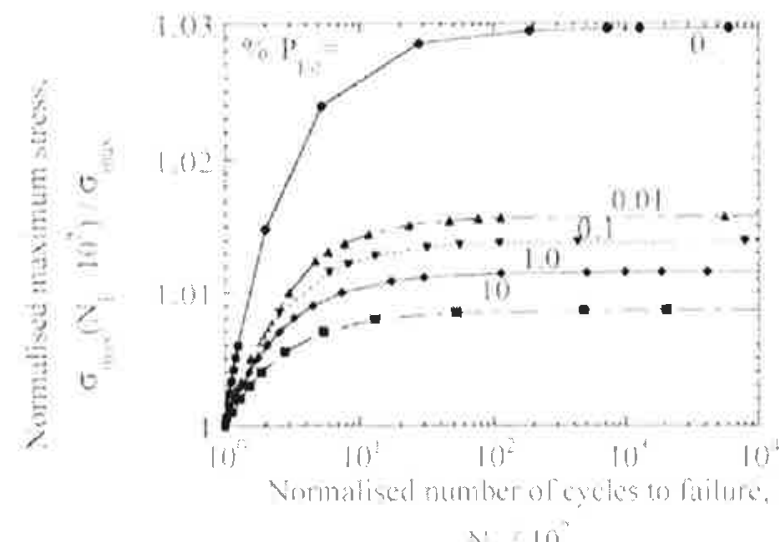

Fig. 5 Change in nolmalized failure stress with normalized number of cycles to failure for different cumulative failure probabilities. 
$10^{9}-10^{11}$ cycles regime is very close to the non-propagation thresholk. The study of the propagation law in this regime shows that the stress intensity factor range is close to zero and that the initial crack size $a_{c 0}$ is close to the non-propagation size $a_{\mathrm{th}}[\mathrm{sec} \mathrm{Eq}$. (8)].

'The effects on the cumulative fillure probability' $P_{P}$ : of the Haw size distribution, the volume of the structure and the stress hetcrogeneity within the structure, respectively (or DVI l effects) are discussed in detail in the following section by considering Eqs (8) and (9) in the $\checkmark \mathrm{HCF}$ regime.

\section{DVH EFFECTS}

The liaw size distribution is very important for specimens and also for complex structures in VICT. The value of the paraneters of the Haw sire elistribution really depends upon the mantafacturing process. Hindurance maps will show how to treat this problem. Besides, in VHCF, SG cast iron behaves like a britele material. For such a condition, the volune of the structure is also an important parameter, Lastly, for a complex structure, some volume elements are subjected to more or less high tension while others are subjected to compression. It follows that a study of the stress ficld heterogencity is also necessary.

\section{The $\mathrm{D}$ effect}

for tested specimens, one couple $(\alpha, \beta)$ (i.e. nne flaw size distrilution) was determined. I Towever; it is most likely that more than one flaw size distribution is needed to describe the initial state of a complex component, e.g. suspension arm. The present probabilistic model allows one to take account of such a situation.

l'or a given number of cycles to failure (here $N_{1:} \rightarrow+\infty$ ), and a constant cumblative failure probability $P_{F 0}$ (e.g. $0.01 \%)$, it is possible to associate a stress level to a couple $(\alpha, \beta)$ when the load ratio $R$ is chosen. These endurance maps correspond to constant values of the ration $\sigma_{11 \mathrm{a} x} / S_{1 \mathrm{~h}} \mathrm{for}$ a given valuc of $P_{\mathrm{T}(0)}$. For each stress level, a safety boundary can be drawn. Below a curve representing a given ratio $\sigma_{\text {max }} / S_{11}$, there is no failure; above it, there is failure when $P_{\mathrm{J} \text { if }}$ is equal to $0.01 \%$ (Fig. 6), as the assumed crack propagation law is deterministic. Hence, the results obtained from latigue tests on specinens can be extrapolated to industrial components characterized by various flaw size distributions.

'To draw this endurance map, an important coeflicient is needed: the endurance limit $S_{1 \mathrm{~L}}$ for a failure probability $P_{\mathrm{T} 0}=0 \%$. 'I his last value is directly linked to the threshold stress intensity lactor $K_{\mathrm{t}}$ and a threshold flaw size $a_{\mathrm{h}} \mathrm{h}$. The value of $S_{\mathrm{Lh}}$ depends on the material microstrueture. It is worth noting that for small flaw sizes (i.e.

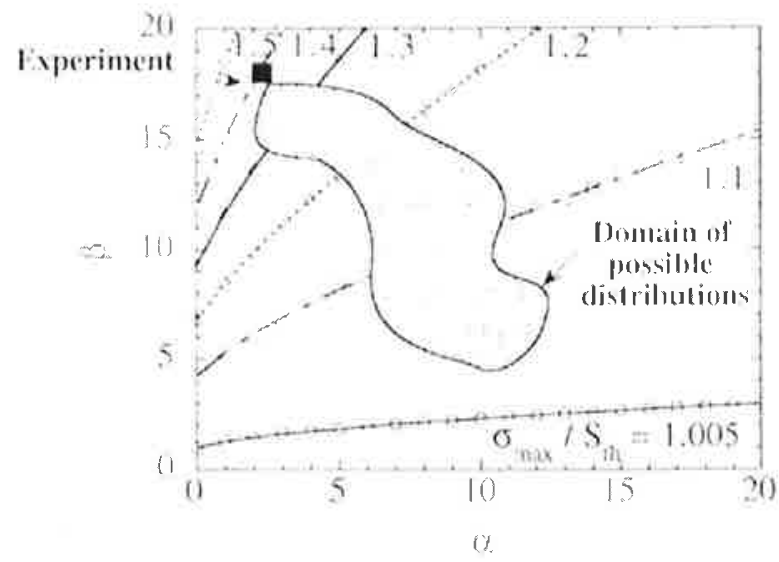

Fig. 6 lindurance map giving different contours of the nomalised stress $\sigma_{112 \mathrm{x}} / S_{1 / \mathrm{L}}$ when $P_{100}=0.01 \%$. The symbol 国 clemotes an experiment.

typieally $a_{0} \leqslant 500$ fun) the value of $K_{\text {th }}$ is inclependent of the initial flaw size. ${ }^{+}$For larger sizes (i.e. $\sigma_{\lambda 1} \geqslant 500 \mu \mathrm{m}$ ), the value of $K_{11}$ increnses with flaw sizes up to a constant value. ${ }^{+, r}$ Howcrer, in all cases the Paris' regime is olutained" (Fig. 7). Therefore, the normalizing stress $S_{\text {Ih }}$ will vary with $a_{M}$ in gencral situations.

\section{The $V$ effect}

In the VHCli regine, the material has a brittle fracture appearance. We can suppose that it is governed by the weakest link assumption? "Therefore, the higher the volume, the higher the probability of finding large flaws and the lower the mean failure stress. This effect is well known for concerete and ceramic materials, ${ }^{1-13}$ and can be gencralised to VHICI of materials whose failure is due to randomly distributed defects.

This result can be shown by considering a crack embedded in a semi-infinite space and subjected to uniaxial cyclic loading, For different diameters of samples $(\Phi)$ and a given stress lavel $\left(\sigma_{\text {Inan }}=350 \mathrm{MPa}\right)$, Fig. 8

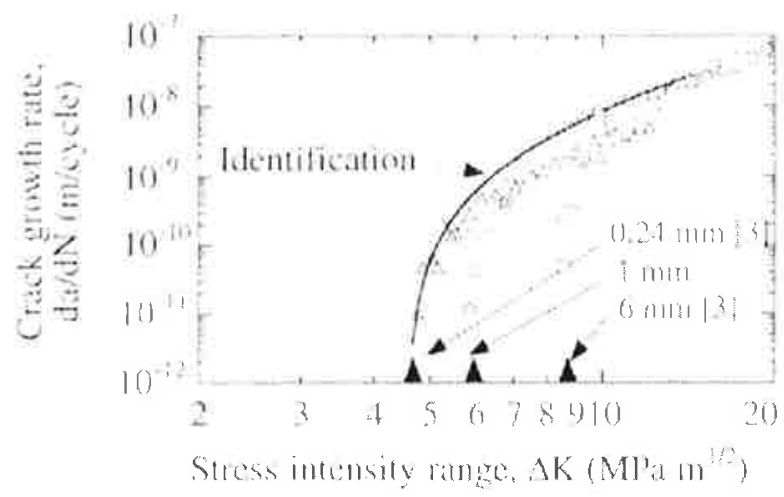

Fig. 7 Evolution of the eriack growth rate for dilferent initial flaw sizes $a_{0}$. 


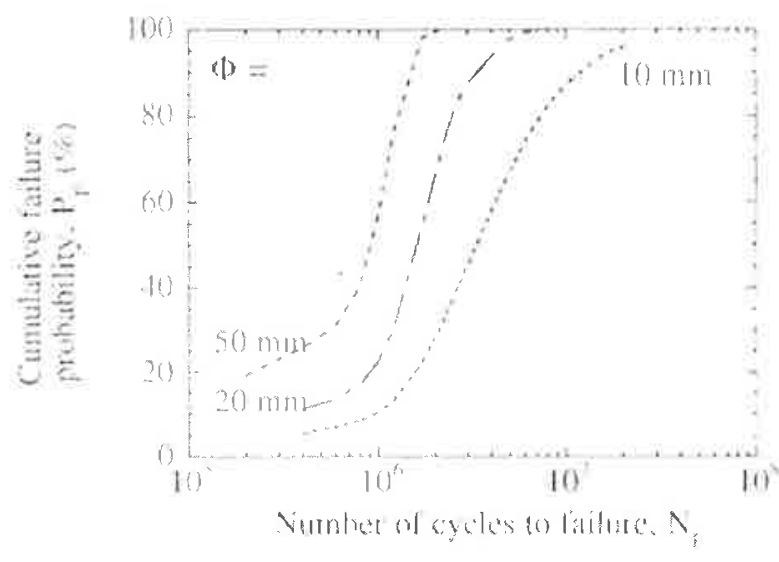

Fig. 8 Volume effect preelicterl for different sample diamerers.

shows that the higher the volume, the higher the failure probabilitics for a given number of cycles to failure. 'Iherefore, the geometry, and in particular the volume, are very important features for the fatigue behaviour of complex structures.

\section{The $\mathbf{H}$ effect}

'The effect of the loading patten on the failure probability is now discussed. Under the condition that $P_{\mathrm{Ir} 0} \ll 1$ and the flaw size is bounded by $a_{M}$, the bela flaw size distribution can be approximated by

$f_{0}(a) \cong \frac{W\left(a_{M}-a\right)^{\beta}}{a_{M}^{k+1}}$

The cumulative failure probability of a volume element becomes

$P_{\text {10 }}=\frac{W}{\beta+1}\left[1-\left(\frac{S_{\text {1 }}}{\sigma_{\text {max }}}\right)^{\beta+1}\right]$

When the stress level $\sigma_{\text {max }}$ is close to $S_{1 h}$, F. (14) can be rewritten as

$P_{\mathrm{Fo} O}=\left[\frac{\left\langle\sigma_{\max }-S_{\mathrm{th}}\right\rangle}{\sigma_{0}}\right]^{h+1}$

with $\sigma_{0}=\frac{S_{\text {ih }}}{2}\left(\frac{W}{\beta+1}\right)^{1 /(\beta+1)}$

Equation (15) corresponcls to a threc-paraneter Weibull law. 'The parameter $\beta$ grives the tenclency of the initial Haw distribution for large faws (i.e. $a \cong a_{M}$ ). By using E.y. (13), the failure probability of a structure $\Omega$ can be written as

$$
\begin{aligned}
& P_{\mathrm{F}}=1-\exp \left[-\frac{H_{\beta+1}^{*} V}{V_{0}}\left(\frac{\left\langle\sigma_{\mathrm{F}}-S_{\mathrm{rl}}\right\rangle}{\sigma_{0}}\right)^{\beta+1}\right], \\
& \sigma_{\mathrm{F}}=\max _{M \in \Omega}\left\{\sigma_{\max }(M)\right\}
\end{aligned}
$$

with

$$
\left.H_{\beta+1}^{*}=\frac{1}{V} \iiint_{\Omega} \frac{\left\langle\sigma_{\max }(M)-S_{\mathrm{th}}\right\rangle^{\beta+1}}{\left\langle\sigma_{\mathrm{F}}-S_{\mathrm{th}}\right\rangle^{\beta+1}} \mathrm{~d} V \quad \text { if } \sigma_{\mathrm{F}}\right\rangle S_{\mathrm{th}}
$$

where $H_{j+1}^{*}$ is a stress heterogeneity factor which depends upon the load type and load level. The corresponding effective volume $V_{\text {eff }}^{*}$ is given by

$V_{\mathrm{eff}}^{*}=H_{p+1}^{*} V$

The effective volume $V_{\text {ell }}^{*}$ is also dependent on the load level. In simple cases, e.g. pure tension, this volume is equal to zero, when $\sigma_{\mathrm{F}} \leqslant S_{\mathrm{ih}}$, and is equal to $V$ when $\sigma_{1}>S_{\text {th. }}$. The previous results will be applied to rotary bending $(R=-1)$ of cylindrical samples. In this case, when $\sigma_{\mathrm{E}}>S_{\mathrm{th}}$, the parameter $H_{i+1}^{*}$ can be expressed by

$H_{\beta+1}^{*}=H_{\beta+1}\left(1-\frac{S_{\mathrm{th}}}{\sigma_{\mathrm{F}}}\right)\left[1+\frac{S_{\mathrm{th}}}{\sigma_{\mathrm{F}}(\beta+2)}\right]$

with $H_{\beta+1}=\frac{2}{\beta+3}$

The stress heterogeneity factor is a unique parameter characterizing the effeet of loading patterns on the failure probability. For a given volume and defect distribution, the more heterogeneous the stress field is, the lower the probability of finding a critical defect in the most loaded area, hence, the lower the stress heterogeneity factor [Eq. (17)] and the failure probability [Eq. (16)].

\section{The suspension arm}

'The previous results are applicd to a suspension arm by using ASTAR (Fig. 5). In lïg, 6, the frey surface represents a schematic of the comain of possible flaw distribution in this structure. By computing the stress

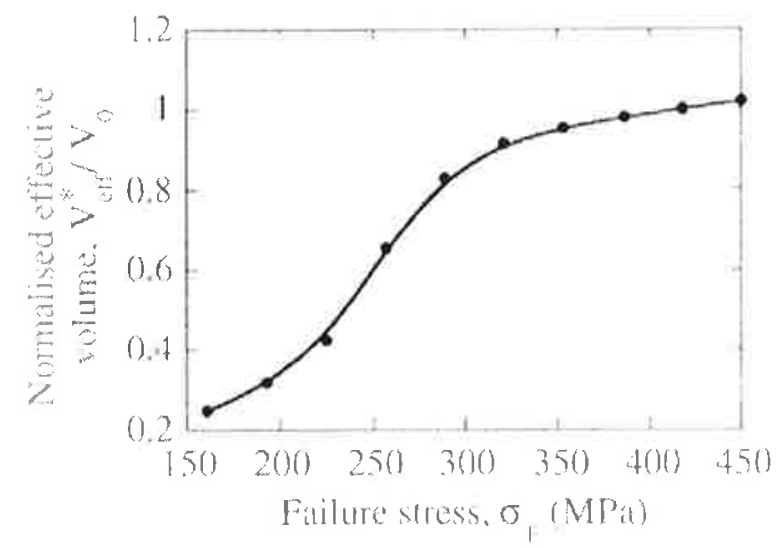

Fig. 9 Change in normalized effective volume $V_{\text {elf }}^{*} / I_{0}^{*}$ with the failure stress $\sigma_{1}$ for a suspension alm with $R=0.1$. 


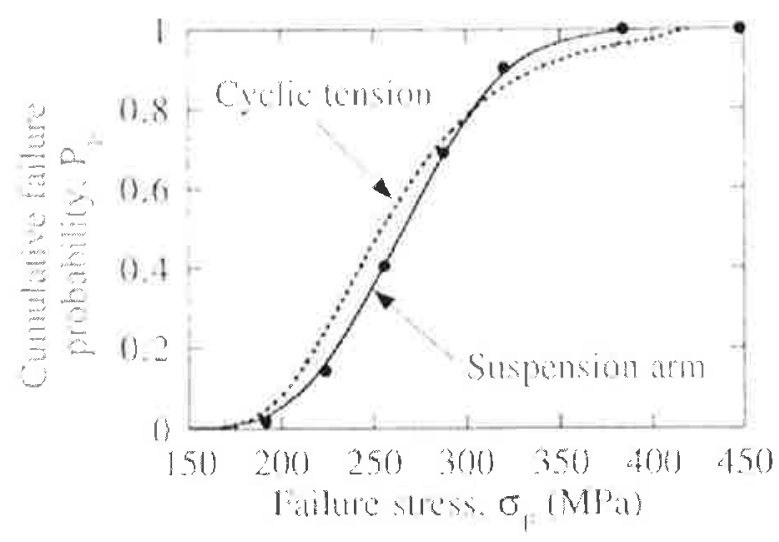

Fig. 10 Comparison of the change in the cumulative failure probability with the lailure stress for a suspension arm incl al specimen subjected to cyclic tension when $k=0.1$.

level at cach integration point of a Fif calculation, it can be checked whether the endurance limits are reached or not. In Fig. 9, the combined $V$ and $I$ effects are taken into account by computing the effective volume for the suspension artm. The value of the effective volume remains close to the volume $V_{0}$ of specimens tested in cyclic purc tension $(R=0,1)$. This result cxplains why, in the VHCF regine, the values of the failure stresses are almost identical in both cases (Fig. 10).

\section{CONCLUSIONS AND PERSPECTIVES}

From this study, the main results are:

1 For the case of suspension arms, predictions are conservative. The main reasoms for the discrepancies are the following: different Haw populations can be present in the suspension arms when eompared to the samples; the residual stresses are not modelled; the effect of the free surface is not accounted for in the vicinity of the as-cast surface where the graphite microstructure is degenerated. When considering shot-peening, the $F-N$ eurves will be rlisplaced in the right way hecause the pecning effect allows one to induce compressive residual stresses which delay crack propration.

2 The extrapolation of lifetimes to $10^{\prime \prime}-10^{11}$ cycles based on results obtained from rests up to $10^{7}$ cycles shows that any crror will not be significant even for very small values of the cumulative failure probability.

3 'The flaw sto distribution, volume and stress heterogeneity (DVI) effects at very high number of cycles to bilure (VICF) are just as significant as in the HCF regime.

To conclude, endurance maps should be established for automatic use in the automotive industry. 'lhese maps will help to interpret non-destructive tests, to improve the manufacturing process and the design process itsclf. 'Therefore, such a lifing procedure could provide some guidelines on whether to reject or aceept a cast component.

However, according to microscopic observations, llaws close to the free surface generally lead to failure. "The introduction of microstructural parameters (including shot-peening parameters) in the propagntion law appears a natural development to the above-presented probatilistic approach for the prediction of the VHCF and ICIF behaviour of cast components.

\section{Acknowledgements}

This work was supported by Renault through contract CNRS/1996/014 (H5.24.12) with LH'T-Cachan. The authors are grateful to Dr A. S. Béranger and I) $\mathrm{H}$. Yaacoub Agha for uscful discussions.

\section{REFERENCES}

I S.-I. Lai and M. O. Wang (1992) Relistility Anolysss in Engintering Applicatiuns, Vaun Norstrand Rheinhold, Ncw Yorl, USA.

2 A. M. Fereudenthal (1968) Statistical approdech to britte Fracture.

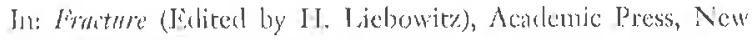
York, LSA, Vol. 2, pp, 591-61\%.

3 F. Fithl and D. Matruis (1992) A stitisticil inpretrach to the rupture of britule manerials. Eur: 7. Meth. A/Solids 11, 753-765.

4 P. Clément, J.-P. Angeli and A. Pineau (1984) Short erack behaviour in nodulall cast iron. Fatigue Fingng Hater Strat. $7,251-265$

5 J. Pellas, G. Baudlin and M. Robert (1977) Mesure el calcul du seuil cle fissuration apress surcharge. Rerberche Acrospetiale 3, $19 !-201$.

6 H. Yaacoule Agtha, A.-S. Bérangere, R. Billardon and I: Hild (1998) Jigh-cyele fatigue behaviour of spheroidal graphite cast

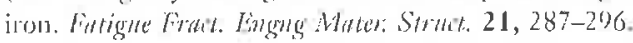

7 K. J, Millor (1903) The two rhresholds of firigue behaviour.

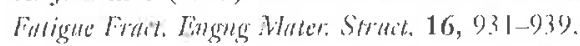

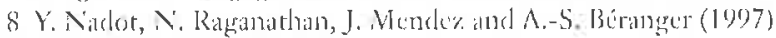
A studly of natural cracks initiated on casting defects by erack lion matking. Scripha Water, 37, 549-553.

9) K. J. Miller and R. Nkid (1996) 'The alplicintion of micrestrucetural fiace ure meehanies to varinus metal surface states. Proc. R. Soi, lond. A 452, 1411-14.32

10 W. II. Press, S. A. 'Teukolsky, W. 'L. Veuerling and B. P. litannery (1992) Numeriat Retipes in fiortran, Cambridge University P'ress, Cambrielge, USA.

11 V. Katlecek and Z. Spleta (1967) liffece of size and shape of test specimens on the direce tensile strength of conerete. Bimlt. RILLM 36, 175-184.

12 5. LiJtermite (1973) Influence de lia dimension absoluc sur lit

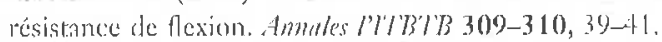

13 Y. Katamian and Y. J Jartory (1982) Iiflects of specimen size on streneth of sinteres silicon nitricle. C. .7. Am. Cerrm. Soc 65, C. $-164+-\mathrm{C}-16.5$. 